\title{
Dietary Effect of Antibiotic Growth Promoter and Essential Oil on Growth Performance, Carcass Traits and Some Physiological Indicators in Broilers
}

\author{
Mohammed H. Alzawqari ${ }^{1,2 *}$ (D), Mohamed H. Al-Zaim¹ (iD), Maher M. Hamoda ${ }^{1}$, Mahmoud M. Yusuf $^{1}$, \\ Mohammed Fouad ${ }^{1}$, Mohamed B. Abu Khalifa ${ }^{1}$ and Ahmed A. Saleh ${ }^{1}$ \\ ${ }^{1}$ Department of Poultry Production, Faculty of Agriculture, Kafrelsheikh University, 333516, Kafrelsheikh, \\ Egypt \\ ${ }^{2}$ Department of Animal Production, Faculty of Agriculture and Food Sciences, Ibb University, Ibb, Yemen
}

"Correspondence: m.alzawqari@gmail.com

(E-mail: m.alzawqari@gmail.com)

Received: $31 / 08 / 2021$

Revised: $\quad 14 / 09 / 2021$

Accepted: 16/09/2021

Published: 20/09/2021

\begin{abstract}
In this bioassay, we assessed the comparative effect of antibiotic growth promoter (AGP) and essential oil (EO) addition on the growth performance, carcass traits, and some physiological indicators in the male Ross 308 broilers. A total of 90 healthy chicks ( 1 day of age) were randomly allocated to three groups, each comprising 6 replicates of 5 chicks. The first group was a control without any additive in water or feed, the second one was offered a drinking water with $0.5 \mathrm{~g} / \mathrm{l} / \mathrm{day}$ of antibiotic, and the third one was supplied a drinking water with $0.5 \mathrm{ml} / \mathrm{liter}$ of EO. In this study, neither AGP nor EO supplementation affected BW, BWG, FI, and FCR $(p<0.05)$ compared with those fed the control diet group. AGP and EO supplemented diets had no significant effect on the carcass, breast and thigh muscles, liver, gizzard, heart spleen, and abdominal fat weight $(p<0.05)$. All the blood plasma concentrations under this study were not affected $(p<0.05)$ by AGP and EO supplementations compared to the untreated control group. In conclusion, it seems that there were no significant differences between the use of AGP or EO supplementation compared with the control group. Therefore, finding from this study demonstrated that essential oil (EO) could be used as a substitute for colistin antibiotic growth promoters (AGP) for broilers, and it's the best strategic way to achieve healthy hygiene meat production free of antibiotic residues.
\end{abstract}

Keywords: broilers; antibiotic growth promoters (AGP); essential oil (EO); growth performance; physiological indicators 


\section{Introduction}

For decades, antibiotics have played an important role as a growth and health enhancer in animal and poultry production (Attia et al., 2017a, 2017b). Colistin is one of the most often used antibiotics in the poultry industry and the last kind of antibiotic used to treat multidrug-resistant bacterial infections (Kumar et al., 2020). On the one hand, the most important benefits of adding colistin antibiotic to broiler diets at subtherapeutic levels appear to be an increase in growth performance and gut function, as well as enhancing gut morphology and health (Hung, 2020). In contrast, colistin use by animals and poultry may result in huge amounts of colistin and resistant bacteria being excreted into the environment via feces, leading to the spread of colistin resistance among people (Peng et al., 2021). After learning about the negative consequences of antibiotic residues inside an animal's body and the increased resistance of pathogens to these residues, people began to be concerned about their use. (Attia et al., 2018; 2019). It was first banned by the European Union in 2006, with a request to investigate suitable alternatives to antibiotics for use in animal feed (Barug et al., 2006; Yang et al., 2019).

As a result, poultry production faced numerous challenges, including decreased growth performance, disease resistance, and financial loss, increasing the demand to create safe and effective techniques for maintaining animal intestinal health. Additionally, this ban of antibiotic use in poultry prompted researchers to look for alternative substances such as organic acidifiers, probiotics, prebiotics, enzymes, medicinal herbs, and associated EOs (Pandey et al., 2019; Attia and Al-Harthi, 2015; Diarra and Malouin, 2014). Accordingly, the poultry industry has set a goal of replacing antibiotic performance enhancers with other safe and natural chemicals that have multiple properties and uses and can be used as growth promoters (Adaszyńska-Skwirzyńska and Szczerbińska., 2017).

Today, prove with evidence-based studies show that the use of EOs worldwide is increasingly focused on poultry for improvement in production and modulation of antioxidant status (Dhama et al., 2015; Attia et al., 2019). Bozkurt et al., (2009) displayed those certain effective supplements, such as medicinal herbs and associated EOs, were gradually used in antibiotic substitution diets.

EOs are colorless liquids composed mostly of aromatic and volatile particles found in the flowers, seeds, stems, bark, husks, or the entire plant (Attia et al., 2019; Sánchez-González et al., 2011). Distillation, fermentation, extraction with solvents or steam are some of the methods used to isolate the EOs from plants. It is noteworthy that EOs contain two types of compounds terpenes and phenylpropenes. Moreover, factors influencing EOs variations include plant species, physical and chemical soil conditions, harvest timing, plant maturity, drying technology, storage duration, and extraction techniques (Namdeo et al., 2020). Medicinal plants and their EOs, known as phytobiotics, are suitable substitutes for growth-promoting antibiotics in broiler diets or drinking water (Grashorn. 2010; Alali et al., 2013; Attia and Al-Harthi, 2015; Galal et al., 2016). Phytobiotics in addition to the growth and production performance of poultry can cause positive changes in other areas such as health status (Willis et al., 2007; Grashorn, 2010; AdaszyńskaSkwirzyńska and Szczerbińska., 2017), intestinal microbial population (Nazzaro et al., 2013; Patel, 2015), serum concentration of antibodies to viral diseases, biochemical parameters and hematological (Demir et al., 2008; El-Ghousein and AL-Beitawi., 2009).

Given the inconsistency of results from previous studies and because of limited studies of the comparison between AGP and 
EO impact on growth performance, carcass characteristics, and physiological indices in the broiler, further research is necessary. Adding EOs may have beneficial effects on the anti-pathogenic bacteria and antioxidant status of broilers, nevertheless, analysis of production performance, carcass characteristics and some physiological indicators are important tools also for assessing the health status of broilers.

The main objective of our research study, thus, was to assess the effect of antibiotic growth promoters (AGP) and essential oil (EO) in comparison with AGP on growth performance, carcass traits and some physiological indicators in broilers.

\section{Material and methods}

The current research study was carried out under the approval of the Local Experimental Animals Care Ethics Committee and performed in compliance with the guidelines of Kafrelsheikh University, Egypt (Number 4/2016EC).

\subsection{Supplements preparation:}

Colistin antibiotic (Colistin Sulfate 4800000 IU) proved from INTERMEDICAVET Company for animal health products, Makram Eubeed St., Cairo, EGYPT. The recommended dose in drinking water is $0.5 \mathrm{~g} / \mathrm{l} / \mathrm{day}$. Essential oil (mentocin plus) was proved from Asterpharma company, Egypt. Each 1 Liter contains $10 \mathrm{~g}$ Thymol oil, $83 \mathrm{~g}$ Menthol oil, and $41 \mathrm{~g}$ Eucalyptus oil). The recommendation doses in $0.5 \mathrm{ml} /$ liter drinking water.

\subsection{Birds, diets, and management:}

A total of 90 chicks (1 day old) were randomly allocated to three groups, each comprising 6 replicates of 5 chicks. All the birds were fed commercial pellet diets, $(23$, 21 , and $19 \% \mathrm{CP}$ by 3000,3040 and 3140 $\mathrm{kcal} / \mathrm{kg}$, respectively) formulated to meet the nutrient requirements recommended by Ross 308 broiler nutrition specifications guide (Aviagen, 2019). The first group control without any additive in water or feed, the second one drinking water with antibiotic, and the third one drinking water with EO.
The experimental diet composition during starter, grower and finisher periods, respectively is presented in Table 1 . At the start of each age period of the experiment, the pellet diets were manufactured in the feed factory and stored at standard environmental conditions according to the firm's guidelines. The diets were provided to the birds' ad libitum and were reared in an environmentally controlled room. All birds had the same environmental management (temperature, moisture, ventilation and light).

\subsection{Growth performance:}

Feed intake (FI) was recorded by subtracting the weight of the leftover feed from the total feed, body weight gain (BWG) was recorded in each replicate unit at the beginning and end of each experimental period. Also, the body weight gain (BWG) was recorded body weight at the end from the beginning period and a calculation of the feed conversion ratio (FCR) on the whole, and periodically gain was calculated by using the following formula: FCR = total feed taken/whole live body weight gained. Throughout the experimental phase, the health status and mortalities were measured daily on a regular basis.

\subsection{Carcass organs traits:}

At the end of the experiment, five birds from each treatment were randomly chosen and slaughtered. Eviscerated weight, liver, gizzard, heart, carcass, and abdominal fat were weighted as carcass traits. Based on live body weight, the percentage yield of each part was calculated.

\subsection{Biochemical parameters analysis:}

At slaughtering time, the blood samples $(5 \mathrm{ml})$ were collected and centrifuged at $3000 \mathrm{rpm}$ for 20 minutes. The plasma produced was frozen at $-20^{\circ} \mathrm{C}$ till the time of chemical analysis. Blood parameters including total cholesterol, triglyceride, aspartate aminotransferase (AST) and alanine aminotransferase (ALT), total protein (TP), albumin, and glucose concentrations were measured colorimetrically using 
Table 1. The ingredients and chemical compositions of the commercial basal diets (1-34 d).

\begin{tabular}{|c|c|c|c|}
\hline \multirow{2}{*}{ Ingredient, $\mathrm{g} / \mathrm{kg}$} & Starter & Grower & Finisher \\
\hline & 1-10 days & 11-25 days & 26-34 days \\
\hline Yellow corn, $8.5 \%$ & 532 & 592 & 633 \\
\hline Soybean meal, $46 \%$ & 370 & 317 & 275 \\
\hline Corn gluten meal, $62 \%$ & 25 & 26 & 20 \\
\hline Soybean oil & 28 & 24 & 34 \\
\hline Dicalcium phosphate & 18.0 & 15.5 & 14.0 \\
\hline DL- Methionine, $99 \%$ & 2.7 & 2.0 & 1.9 \\
\hline L-Lysine HCL, 98\% & 2.5 & 2.3 & 2.2 \\
\hline Threonine, $99 \%$ & 1.1 & 0.7 & 0.6 \\
\hline Limestone & 13.6 & 13.3 & 12.0 \\
\hline $\mathrm{NaCl}$ & 2.3 & 2.6 & 2.7 \\
\hline Premix ${ }^{*}$ & 3 & 3 & 3 \\
\hline Sodium bicarbonate & 1.8 & 1.6 & 1.6 \\
\hline Total & 1000 & 1000 & 1000 \\
\hline \multicolumn{4}{|l|}{ Calculated analysis** } \\
\hline Crude protein, $\%$ & 23 & 21 & 19 \\
\hline TME, Kcal/kg diet & 3001 & 3043 & 3142 \\
\hline Calcium, $\%$ & 1.036 & 0.955 & 0.861 \\
\hline Total phosphorus, $\%$ & 0.735 & 0.671 & 0.625 \\
\hline $\mathrm{Na}$ & 0.17 & 0.17 & 0.17 \\
\hline $\mathrm{Cl}$ & 0.18 & 0.20 & 0.20 \\
\hline L-Lysine, \% & 1.47 & 1.31 & 1.17 \\
\hline DL- Methionine, $\%$ & 0.66 & 0.57 & 0.53 \\
\hline
\end{tabular}

commercial kits (Diamond Diagnostics, Egypt) according to the procedure outlined by the manufacturer.

\subsection{Statistical analysis:}

The collected data were analyzed according to a completely randomized design (CRD) using the general linear model (GLM) procedure of the SAS version 9.4 (2016). The significance of means' differences was checked using Tukey's multiple comparison test bases on $\mathrm{p}<0.05$.

\section{Results}

\subsection{Growth performance:}

The effects of AGP and EO supplementation on growth performance in broilers were displayed in Table 2. In this study, neither AGP nor EO supplementation affected growth performance parameters, including BW, BWG, FI and FCR $(p<0.05)$ in the birds on AGP and EO treatments compared the overall experimental period.

\subsection{Carcass traits:}

The results of carcass organ traits are exposed in Table 3. AGP and EO supplemented groups did not affect carcass traits, including carcass, breast and thigh muscles, liver, gizzard, heart spleen, and abdominal fat weight $(p<0.05)$.

\subsection{Plasma parameters:}

Table 4 displays the effect of AGP and EO supplementation on the plasma total protein, albumin, globulin, glucose, total cholesterol, triglyceride, GPT and GOT concentrations. All the plasma parameters concentrations under this study such as total protein, albumin, globulin, glucose, total cholesterol, triglyceride, GPT and GOT were not affected $(p<0.05)$ by AGP and EO supplementation compared to the untreated control group. 
Table 2. Dietary effect of antibiotic growth promoters (AGP) and Essential oil (EO) on growth performance in broilers.

\begin{tabular}{|c|c|c|c|c|c|}
\hline \multirow{2}{*}{ Item } & \multicolumn{3}{|c|}{ Diet treatments } & \multirow{2}{*}{ SEM } & \multirow{2}{*}{ P-Tukey } \\
\hline & Control & AGP & $\mathrm{EO}$ & & \\
\hline Initial Body weight, $\mathrm{g} / \mathrm{b}$ & 39.93 & 39.87 & 39.93 & 0.13 & 0.704 \\
\hline Final body weight, g/35 d & 1858.33 & 1940.00 & 1877.67 & 20.72 & 0.071 \\
\hline Body weight gain, g/b & 1818.47 & 1900.23 & 1837.73 & 20.81 & 0.072 \\
\hline Feed intake, $\mathrm{g} / 35 \mathrm{~d}$ & 3171.33 & 3170.00 & 3157.67 & 44.57 & 0.972 \\
\hline Feed conversion ratio, g/g & 1.71 & 1.64 & 1.68 & 0.02 & 0.168 \\
\hline
\end{tabular}

a-b The means placed at the rows with different superscript letters are significantly different $(P>0.05)$; SEM, standard error of the means; Control, a basal diet without supplements; AGP, antibiotic growth promoters; EO, essential oil.

Table 3. Dietary effect of antibiotic growth promoters (AGP) and Essential oil (EO) on carcass traits in broilers.

\begin{tabular}{lccccc}
\hline \multirow{2}{*}{ Item } & \multicolumn{3}{c}{ Diet treatments } & \multirow{2}{*}{ SEM } & P-Tukey \\
\cline { 2 - 5 } & Control & AGP & EO & & 0.927 \\
Carcass weight, g/100g BW & 66.22 & 66.53 & 66.34 & 0.56 & 0.877 \\
Breast muscle weight, g/100g BW & 23.56 & 23.28 & 23.11 & 0.62 & 0.328 \\
Thigh muscle weight, g/100g BW & 16.17 & 16.88 & 16.35 & 0.21 & 0.998 \\
Liver weight, g/100g BW & 2.80 & 2.82 & 2.81 & 0.21 & 0.971 \\
Gizzard weight, g/100g BW & 1.27 & 1.25 & 1.27 & 0.06 & 0.422 \\
Heart weight, g/100g BW & 0.58 & 0.59 & 0.62 & 0.02 & 0.824 \\
Spleen weight, g/100g BW & 0.07 & 0.06 & 0.06 & 0.02 & 0.836 \\
Abdominal fat weight, g/100g BW & 1.39 & 1.34 & 1.32 & 0.08 & \\
a-b The means placed at the rows with different superscript letters are significantly different $(P>0.05) ;$ SEM, \\
standard error of the means; Control, a basal diet without supplements; AGP, antibiotic growth promoters; EO, \\
essential oil.
\end{tabular}

Table 4. Dietary effect of antibiotic growth promoters (AGP) and Essential oil (EO) on plasma parameters in broilers.

\begin{tabular}{|c|c|c|c|c|c|}
\hline \multirow{2}{*}{ Item } & \multicolumn{3}{|c|}{ Diet treatments } & \multirow{2}{*}{ SEM } & \multirow{2}{*}{ P-Tukey } \\
\hline & Control & AGP & EO & & \\
\hline Total protein, g/dL & 4.47 & 4.60 & 4.03 & 0.26 & 0.213 \\
\hline Albumin, $\mathrm{g} / \mathrm{dL}$ & 1.44 & 1.54 & 1.56 & 0.03 & 0.095 \\
\hline Globulin, g/dL & 3.03 & 3.06 & 3.47 & 0.19 & 0.274 \\
\hline Glucose, $\mathrm{mg} / \mathrm{dL}$ & 152.33 & 154.67 & 151.33 & 9.21 & 0.862 \\
\hline Total cholesterol, mg/dL & 122.00 & 125.33 & 122.33 & 5.75 & 0.905 \\
\hline Triglyceride, mg/dL & 6.23 & 5.40 & 4.30 & 0.66 & 0.198 \\
\hline $\mathrm{GPT}, \mathrm{mg} / \mathrm{dL}$ & 6.27 & 6.66 & 5.83 & 0.58 & 0.619 \\
\hline $\mathrm{GOT}, \mathrm{mg} / \mathrm{dL}$ & 249.33 & 241.33 & 250.67 & 21.17 & 0.945 \\
\hline
\end{tabular}

\section{Discussion}

\subsection{Growth performance:}

The present study aimed to evaluate the comparative effect of antibiotic growth promoters (AGP) and essential oils (EO) and whether substituting antibiotics with EOs would have the same beneficial effects over antibiotics on growth performance, carcass traits, and some physiological indicators in male Ross 308. There were no significant differences $(p<0.05)$ in all growth performance parameters between treated groups compared with the control group. Except, the APG and EO groups numerically increased FBW and BWG than the control group, Similar results were observed by Botsoglou et al., (2002) who reported that dietary oregano EO supplementation to broilers had no positive effect on growth performance. Hernandez-Coronado et al. 
(2019) also found that the addition of dietary oregano EO had no major effects on broilers' growth and that differential BWG effects could be determined by differences in EO levels and ingredients in diets. Another study found that adding thyme oil did not affect broiler BWG (Cross et al., 2003). According to Lee et al. (2003), $200 \mathrm{mg} / \mathrm{kg}$ of thymol in the diet did not affect the BWG, FI, or FCR of female broilers. In contrast to our findings, treatment with $1000 \mathrm{mg} / \mathrm{kg}$ thyme EO enhanced BWG while lowering FI by about 10\% (Cross et al., 2007; Hashemipour et al., 2013). Studies have shown that EO supplementation in the diet improves their growth performance by encouraging digestive enzyme secretion that results in improved nutrient digestion, digestive transmission rate (Attia et al., 2017a; Jamroz et al., 2005). The antibacterial effect of EO and the stimulation of several digestive enzymes, which improve nutrition utilization, lead to an increase in body weight growth (Attia et al., 2019; Hernandez et al., 2004). However, Tiihonen et al. (2010) found that include $\mathrm{EO}$ in broiler diets reduces the growth of pathogenic bacteria while increasing the growth of beneficial gut microbiota, which improves broiler growth performance. The stability of EOs and AGP during feed processing where researchers reported that significant loss of activity of EOs was caused by a pelleting temperature of $58{ }^{\circ} \mathrm{C}$ (Maenner et al., 2011; Cromwell., 2002; Attia and Al-Harthi, 2015). The lack of performance effects of AGP and EO could be explained by levels of the supplemental in the diet, environmental, and feed processing conditions.

\subsection{Carcass traits:}

A positive relationship has been established between improving poultry meat quality by increasing muscle and growth while reducing abdominal fat content (Musa et al., 2006). The current findings on the effect of AGP and EO on carcass organs were consistent with the findings of Alp et al., (2012) they reported that the addition of $300 \mathrm{mg} / \mathrm{kg}$ of oregano EO did not have a significant impact on the carcass characteristics. On the other hand, several studies showed the positive effects of EOs supplementation on carcass traits in broilers (Sang-oh et al. 2013; Khattak et al., 2014; Peng et al., 2016). Whatever the case, the low concentrations of additives or the reduced effectiveness of AGP and EO due to the high temperature during the feed processing production possibly explain why the additives did not influence carcass attributes.

\subsection{Plasma parameters:}

Supplementation of AGP and EO did not affect total protein, albumin, globulin, glucose, total cholesterol, triglyceride, GPT, and GOT in broilers during the experimental period. These findings were comparable to those of Lee et al., (2003, 2004) and Bampidis et al., (2005), who showed no significant variations in serum cholesterol, HDL, or triglyceride levels across groups. Meanwhile, other studies showed a positive effect on reducing the plasma total protein and globulins due to supplementation of Eos to broiler's diets (Attia et al., 2018; Ghazalah and Ali., 2008). There are contradictory results regarding the effect of dietary EO to broiler diets on plasma biochemistry parameters, due to the differences between the types of essential oils according to the type of plants extracted, as well as the concentration of active substances in them and the extent of the effect of the feed processing temperature.

\section{Conclusions}

In conclusion, this study demonstrated that no differences in the parameters including growth performance, carcass traits and physiological indicators between all the treatment groups because of the use of $0.5 \mathrm{~g} / \mathrm{l} /$ day of AGP or $0.5 \mathrm{mg} / \mathrm{l}$ of EO in broilers' diets. Although the APG and EO groups had higher FBW and BWG than the control group, the differences were not statistically significant. Nevertheless, no negative effect was observed when the AGP or EO supplementation was in the broilers diet. Therefore, finding from this study 
demonstrated that essential oil (EO) could be used as a replacement for Colistin antibiotic growth promoters (AGP) in broilers commercial diets, and it's the best strategic way to achieve healthy hygiene meat production free of antibiotic residues.

\section{Conflict of interest statement}

This manuscript has no conflicts of interest.

\section{Data availability statement:}

All data sets collected and analyzed during the current study are available from the corresponding author on reasonable request.

\section{References}

Attia, Y., Bakhashwain, A. \& Bertu, N. (2018). Utilisation of thyme powder (Thyme vulgaris L.) as a growth promoter alternative to antibiotics for broiler chickens raised in a hot climate. European Poultry Science, 82.

Attia, Y. A., \& Al-Harthi, M. (2015). Nigella seed oil as an alternative to antibiotic growth promoters for broiler Chickens. Europ. Poult. Sci., 79(80): 10.1399.

Attia, Y. A., Al-Harthi, M. A., \& Hassan, S. S. (2017). Turmeric (Curcuma longa Linn.) as a phytogenic growth promoter alternative for antibiotic and comparable to mannan oligosaccharides for broiler chicks. Revista mexicana de ciencias pecuarias, 8(1), 11-21.

Attia, Y. A., Bakhashwain, A. A., \& Bertu, N. K. (2017). Thyme oil (Thyme vulgaris L.) as a natural growth promoter for broiler chickens reared under hot climate. Italian Journal of Animal Science, 16(2), 275-282.

Adaszyńska-Skwirzyńska, M., \& Szczerbińska, D. (2017). Use of essential oils in broiler chicken production-a review. Annals of Animal Science, 17(2), 317.

Attia, Y., Al-Harthi, M., \& El-Kelawy, M. (2019). Utilisation of essential oils as a natural growth promoter for broiler chickens. Italian Journal of Animal Science, 18(1), 1005-1012.
Alali, W., Hofacre, C., Mathis, G., \& Faltys, G. (2013). Effect of essential oil compound on shedding and colonization of Salmonella enterica serovar Heidelberg in broilers. Poultry science, 92(3), 836841.

Alp, M., Midilli, M., Kocabağlı, N., Yılmaz, H., Turan, N., Gargilı, A., \& Acar, N. (2012). The effects of dietary oregano essential oil on live performance, carcass yield, serum immunoglobulin $\mathrm{G}$ level, and oocyst count in broilers. Journal of Applied Poultry Research, 21(3), 630636.

Aviagen. (2019). Ross 308 Broiler Management Guide. Available at (www.aviagen.com).

Bampidis, V., Christodoulou, V., FlorouPaneri, P., Christaki, E., Chatzopoulou, P., Tsiligianni, T., \& Spais, A. (2005). Effect of dietary dried oregano leaves on growth performance, carcase characteristics and serum cholesterol of female early maturing turkeys. British Poultry Science, 46(5), 595-601.

Barug, D., de Jong, J., Kies, A., \& Verstegen, M. (2006). Antimicrobial growth promoters: where do we go from here? : Wageningen Academic Publishers.

Botsoglou, N., Florou-Paneri, P., Christaki, E., Fletouris, D., \& Spais, A. (2002). Effect of dietary oregano essential oil on performance of chickens and on ironinduced lipid oxidation of breast, thigh and abdominal fat tissues. British Poultry Science, 43(2), 223-230.

Bozkurt, M., Alçiçek, A., Çabuk, M., Küçükyilmaz, K., \& Çatli, A. (2009). Effect of an herbal essential oil mixture on growth, laying traits, and egg hatching characteristics of broiler breeders. Poultry science, 88(11), 2368-2374.

Cromwell, G.L. (2002). Why and how antibiotics are used in swine production. Animal Biotechnology, 13(1), 7-27.

Cross, D., McDevitt, R., Hillman, K., \& Acamovic, T. (2007). The effect of herbs and their associated essential oils on 
performance, dietary digestibility and gut microflora in chickens from 7 to 28 days of age. British Poultry Science, 48(4), 496-506.

Cross, D., Svoboda, K., McDevitt, R., \& Acamovic, T. (2003). The performance of chickens fed diets with and without thyme oil and enzymes. British Poultry Science, 44(S1), 18-19.

Demir, E., Kilinc, K., Yildirim, Y., Dincer, F., \& Eseceli, H. (2008). Comparative effects of mint, sage, thyme and flavomycin in wheat-based broiler diets. Archiva Zootechnica, 11(3), 54-63.

Dhama, K., Latheef, S. K., Mani, S., Samad, H. A., Karthik, K., Tiwari, R., . . A Alam, G. M. (2015). Multiple beneficial applications and modes of action of herbs in poultry health and production-A review. International Journal of Pharmacology, 11(3), 152-176.

Diarra, M. S., \& Malouin, F. (2014). Antibiotics in Canadian poultry productions and anticipated alternatives. Frontiers in microbiology, 5, 282.

El-Ghousein, S. S., \& Al-Beitawi, N. A. (2009). The effect of feeding of crushed thyme (Thymus valgaris L) on growth, blood constituents, gastrointestinal tract and carcass characteristics of broiler chickens. The Journal of Poultry Science, 46(2), 100-104.

Galal, A., El-Araby, I., Hassanin, O., \& ElSaid Omar, A. (2016). Positive impact of oregano essential oil on growth performance, humoral immune responses and chicken interferon alpha signalling pathway in broilers. Advances in Animal and Veterinary Sciences, 4(4), 57-65.

Ghazalah, A., \& Ali, A. (2008). Rosemary leaves as a dietary supplement for growth in broiler chickens. International Journal of Poultry Science, 7(3), 234-239.

Grashorn, M. (2010). Use of phytobiotics in broiler nutrition-an alternative to infeed antibiotics. Journal of Animal and Feed Sciences, 19(3), 338-347.

Hashemipour, H., Kermanshahi, H., Golian, A., \& Veldkamp, T. (2013). Effect of thymol and carvacrol feed supplementation on performance, antioxidant enzyme activities, fatty acid composition, digestive enzyme activities, and immune response in broiler chickens. Poultry science, 92(8), 2059-2069.

Hernandez, F., Madrid, J., Garcia, V., Orengo, J., \& Megias, M. (2004). Influence of two plant extracts on broilers performance, digestibility, and digestive organ size. Poultry science, 83(2), 169174.

Hernández-Coronado, A. C., Silva-Vázquez, R., Rangel-Nava, Z. E., HernándezMartínez, C. A., Kawas-Garza, J. R., Hume, M. E., \& Méndez-Zamora, G. (2019). Mexican oregano essential oils given in drinking water on performance, carcass traits, and meat quality of broilers. Poultry science, 98(7), 3050-3058.

Hung, C., Chen, C., \& Chen, B. (2020). Colistin and tylosin enhances disaccharidase activities and improves morphology and permeability of the intestine of broilers. British Poultry Science, 61(4), 465-470.

Jamroz, D., Wiliczkiewicz, A., Wertelecki, T., Orda, J., \& Skorupińska, J. (2005). Use of active substances of plant origin in chicken diets based on maize and locally grown cereals. British Poultry Science, 46(4), 485-493.

Khattak, F., Ronchi, A., Castelli, P., \& Sparks, N. (2014). Effects of natural blend of essential oil on growth performance, blood biochemistry, cecal morphology, and carcass quality of broiler chickens. Poultry science, 93(1), 132-137.

Kumar, H., Chen, B.-H., Kuca, K., Nepovimova, E., Kaushal, A., Nagraik, R., Kumar, A. (2020). Understanding of Colistin Usage in Food Animals and Available Detection Techniques: A Review. Animals, 10(10), 1892.

Lee KW, Everts H, Beynen AC. (2004a) Essential oils in broiler nutrition. Int $J$ Poult Sci, 3(12),738-752.

Lee, K.-W., Everts, H., Kappert, H., Frehner, M., Losa, R., \& Beynen, A. (2003). 
Effects of dietary essential oil components on growth performance, digestive enzymes and lipid metabolism in female broiler chickens. British Poultry Science, 44(3), 450-457.

Maenner, K., Vahjen, W., \& Simon, O. (2011). Studies on the effects of essentialoil-based feed additives on performance, ileal nutrient digestibility, and selected bacterial groups in the gastrointestinal tract of piglets. Journal of animal science, 89(7), 2106-2112.

Musa, H., Chen, G., Cheng, J., Li, B., \& Mekki, D. (2006). Study on carcass characteristics of chicken breeds raised under the intensive condition. Int. J. Poult. Sci, 5(6), 530-533.

Namdeo, S., Baghel, R., Nayak, S., Khare, A., Prakash, R., Pal, A. C., . . . Reddy, B. (2020). Essential oils: an potential substitute to antibiotics growth promoter in broiler diet. Journal of Entomology and Zoology Studies, 8(4), 1643-1649

Nazzaro, F., Fratianni, F., De Martino, L., Coppola, R., \& De Feo, V. (2013). Effect of essential oils on pathogenic bacteria. Pharmaceuticals, 6(12), 1451-1474.

Pandey, A. K., Kumar, P., \& Saxena, M. (2019). Feed additives in animal health. In Nutraceuticals in Veterinary Medicine (pp. 345-362): Springer.

Patel, S. (2015). Plant essential oils and allied volatile fractions as multifunctional additives in meat and fish-based food products: a review. Food Additives \& Contaminants: Part A, 32(7), 1049-1064.

Peng, C., Zuo, S., Qiu, Y., Fu, S., \& Peng, L. (2021). Determination of Colistin in Contents Derived from Gastrointestinal Tract of Feeding Treated Piglet and Broiler. Antibiotics, 10(4), 422.

Peng, Q., Li, J., Li, Z., Duan, Z., \& Wu, Y. (2016). Effects of dietary supplementation with oregano essential oil on growth performance, carcass traits and jejunal morphology in broiler chickens. Animal feed science and technology, 214, 148153.

Sánchez-González, L., Vargas, M., González-Martínez, C., Chiralt, A., \& Chafer, M. (2011). Use of essential oils in bioactive edible coatings: a review. Food Engineering Reviews, 3(1), 1-16.

Sang-Oh, P., Chae-Min, R., Byung-Sung, P., \& Jong, H. (2013). The meat quality and growth performance in broiler chickens fed diet with cinnamon powder. Journal of Environmental biology, 34(1), 127.

SAS Statistical Analysis System. (2016). SAS/STAT® 9.4. User's Guide. SAS Institute Inc. Cary, North Carolina.

Tiihonen, K., Kettunen, H., Bento, M. H. L., Saarinen, M., Lahtinen, S., Ouwehand, A., . . . Rautonen, N. (2010). The effect of feeding essential oils on broiler performance and gut microbiota. British Poultry Science, 51(3), 381-392.

Willis, W. L., Isikhuemhen, O. S., \& Ibrahim, S. A. (2007). Performance assessment of broiler chickens given mushroom extract alone or in combination with probiotics. Poultry science, 86(9), 1856-1860.

Yang, X., Liu, Y., Yan, F., Yang, C., \& Yang, X. (2019). Effects of encapsulated organic acids and essential oils on intestinal barrier, microbial count, and bacterial metabolites in broiler chickens. Poultry science, 98(7), 2858-2865. 